\title{
Research on Hotel Practice Satisfaction and Retention Intention of Undergraduates Majoring in Tourism Management
}

\author{
Chunyan Wang ${ }^{1, a}$ and Qinglan Luo ${ }^{1, b}$ \\ ${ }^{1}$ College of Business Administration, Jilin Engineering Normal University, Changchun City, China \\ a541012329@qq.com, bsunny203@126.com
}

\begin{abstract}
Keywords: Tourism management; Hotel practice; Practice satisfaction; Retention intention; Status survey
\end{abstract}

\begin{abstract}
This study investigates the two-term hotel trainees in five universities (three public universities and two private universities) in Jilin Province. It objectively illustrates the impact of hotel practice satisfaction on their retention intention. The results show that training opportunities, working conditions, development space and attention are positively correlated with hotel practice satisfaction of undergraduates majoring in tourism management. There is a high negative correlation between psychological expectation and practice satisfaction of undergraduates majoring in tourism management. Practice satisfaction not only directly affects the intention to stay hotels, but also plays an intermediary role in the influence of training opportunities, working conditions, development space, degree of attention and psychological expectations on the intention to stay. Finally, this study puts forward different countermeasures and suggestions from three perspectives of hotel, universities and students.
\end{abstract}

\section{Introduction}

With the rapid development of China's tourism industry, the demand for high-quality professionals in tourism enterprises is increasing. While the employment rate of graduates from tourism management is very low in tourism industry. The number of undergraduate majoring in tourism management who are employed in this industry is generally $10-20 \%$. Less than $20 \%$ of them still work in the tourism industry after two years [1]. After graduating from tourism majors, only about $30 \%$ of the total number of graduates engaged in this major [2]. Some studies have found that college students' satisfaction with the hotel industry has declined after practice in hotels, and their confidence in hotel work has declined.

Hotel practice is a compulsory course for tourism management, hotel management and other related majors. It is a process for students to combine professional knowledge with practical work. It is an indispensable part of training hotel professionals. In recent years, the employment rate of undergraduates majoring in tourism management to tourism enterprises, especially hotel enterprises, has been declining year by year, which has aroused widespread concern in the industry and academia [3]. Tourism management professionals are far away from the tourism industry, which has brought great losses and negative effects to the tourism industry [4]. This study investigates the status of undergraduates majoring in Tourism Management in Hotel practice, and then explores the relationship between their job status and their willingness to choose employment in the hotel industry after their practice, that is, whether the hotel practice satisfaction will affect their subsequent intention to choose a career in the hotel industry.

\section{Analysis of Questionnaires}

Sample Survey. The section headings are in boldface capital and lowercase letters. Second level headings are typed as part of the succeeding paragraph (like the subsection heading of this paragraph). From June 2017 to December 2017, the research group conducted a survey on trainees of hotel specialty (orientation) in five universities (three public universities and two private universities) in Jilin Province. 200 questionnaires were sent out and 178 valid questionnaires were received, with an effective rate of $89 \%$. The Cronbach's $\alpha$ coefficient was 0.79 and had high internal consistency. The 
demographic factors of the sample are as follows: women account for $69 \%$, men account for $31 \%$, and the average age of students is 21.8 .

Correlation Analysis between Practice Satisfaction and Retention Intention. Through this survey, it is found that the number of undergraduates majoring in tourism management who choose "to work in hotels with practice satisfaction" and "not to work in hotels with practice dissatisfaction" accounted for the largest proportion of the total number, the sum of which reached 75\%; the respondents who chose "to work in hotels with practice dissatisfaction" and "not to work in hotels with practice satisfaction" accounted for only $25 \%$. This shows that practice satisfaction is an important factor affecting whether trainees stay at the hotel. And the higher the practice satisfaction, the greater the intention to stay at the hotel, otherwise the smaller.

Correlation Analysis between Practice Satisfaction and Training Opportunities. According to the survey of undergraduate students' satisfaction with practice, $37 \%$ of them think that "attaching importance to the cultivation of individual ability" is very important, and the second is "hotel attaching importance to the construction of corporate culture", accounting for $24 \%$. Therefore, training opportunities for hotel practice satisfaction plays a considerable role, and is to promote the role, that is, training opportunities and practice satisfaction is a positive correlation.

In the survey of unsatisfactory factors of undergraduates majoring in Tourism Management in Hotel practice, it was found that the main factors affecting the satisfaction of trainees in hotel practice were "not always the ability to train, no training", accounting for $53 \%$, followed by "unreasonable working hours", accounting for $40 \%$.

In the survey of the relationship between the degree of attachment to hotel practice and the degree of satisfaction of undergraduates majoring in tourism management, it was found that the proportion of "feeling dissatisfied with not being valued" was the largest, accounting for 51\%; followed by "feeling satisfied with being valued", accounting for 39\%; while "valued but feeling dissatisfied" and "not valued but feeling satisfied" only accounted for $10 \%$. Obviously, the greater attention, the higher the degree of satisfaction with practice. The less attention, the lower the degree of satisfaction with practice.

Relationship between Career Development Space and Practice Satisfaction. In the survey of the first job expectations of undergraduates majoring in tourism management, it was found that graduates attached great importance to the development space in their first job after graduation. Among them, the choice of "large development space, acceptable wages" accounted for $46 \%$ of the total. Therefore, in the process of hotel practice, the development space has a great influence on the trainees' satisfaction, and affects the trainees' willingness to stay in the hotel.

Relationship between Psychological Expectation and Practice Satisfaction. The main reason why trainees are unwilling to work in hotels is that they find that the gap between reality and expectation is too big, the space for development is too small, the working hours are disliked and they are not valued. The trainees will have a certain psychological expectation of the hotel before they start their hotel practice. Once they find out that the actual work is not symmetrical with his expectations after the hotel practice, that is to say, there is a big psychological gap between the trainees before and after the practice, which will greatly affect the practice satisfaction of the hotel, and then affect their intention to work in the hotel.

Analysis of the Mediating Role of Practice Satisfaction. In order to study the mediating effect of practice satisfaction on training opportunities, degree of attention, space for development, working conditions and psychological expectations on trainees' intention to stay, further investigation and analysis were conducted. 
Table 1 Survey results of conditions for trainees to improve their practice satisfaction in hotels

\begin{tabular}{|c|l|c|}
\hline No. & Investigation subject & Frequency \\
\hline 1 & Attach importance to staff training & 105 \\
\hline 2 & Providing career development space & 98 \\
\hline 3 & Provide reasonable wages and benefits. & 96 \\
\hline 4 & Attach importance to employees & 88 \\
\hline 5 & Reasonable working hours & 87 \\
\hline 6 & Good working environment & 80 \\
\hline 7 & Improve staff quality and service ability & 61 \\
\hline 8 & Lay stress on enterprise culture construction & 54 \\
\hline 9 & Pay attention to people-oriented management concept & 30 \\
\hline 10 & Good enterprise management mechanism & 28 \\
\hline 11 & Clear division of work & 23 \\
\hline 12 & Reasonable personnel system & 21 \\
\hline 13 & Pay attention to educational background & 18 \\
\hline 14 & Sagacious managers & 13 \\
\hline 15 & Have a wide communication platform & 11 \\
\hline 16 & Be discriminating in one's rewards and punishments & 5 \\
\hline
\end{tabular}

As can be seen from Table 1, the top three are staff training, development space, wages and benefits, attention and working conditions, which have a great impact on trainees' practice satisfaction at the hotel. Once these conditions are met to the greatest extent, trainees' practice satisfaction will rapidly increase to a very high level. According to the above analysis, it is found that hotel practice satisfaction and trainees' willingness to stay have a great positive correlation, that is, the higher the hotel practice satisfaction, the greater the trainee" willingness to stay. So we find that training opportunities, development space, degree of attention and working conditions are important factors to increase practice satisfaction. To sum up, practice satisfaction not only has an impact on the intention to stay, but also plays a mediating role in the impact of training opportunities, development space, degree of attention and working conditions on the intention to stay.

\section{Conclusions}

Statistical analysis and correlation analysis of the questionnaire data show that training opportunities, working conditions, development space and attention are highly positively correlated with hotel practice satisfaction of undergraduates majoring in tourism management; psychological expectation is highly negatively correlated with hotel practice satisfaction of undergraduates majoring in tourism management. Practice satisfaction not only directly affects the intention to stay, but also mediates the influence of training opportunities, working conditions, development space, attention and psychological expectations on the intention to stay. The above conclusions verify that the main reason for the low retention intention of undergraduates majoring in tourism management is the low degree of practice satisfaction.

Using quantitative analysis method, the following suggestions are given from three perspectives.

From the perspective of hotel enterprise. The treatment provided by hotel enterprises for students, as well as the development prospects of students in the enterprise, corporate reputation and professional counterparts, job training, new and old help, attention in the enterprise, etc., all affect the hotel practice satisfaction of undergraduate students majoring in Tourism Management. Therefore, hotel enterprises should appropriately improve the treatment of undergraduates in tourism management, provide 
preferential policies for their career development, attach importance to the career planning of them [5], provide them with more opportunities for learning, participation, training and development, make them feel valued, and form a strong sense of identity and belonging to the hotel. They should try their best to attract and retain the employment of Tourism Management Undergraduates at the hotels.

From the perspective of colleges and universities. Teaching and practice are both factors to cultivate the employment tendency of tourism management undergraduates. Especially, practice plays a more important role in cultivating the employment tendency of tourism management undergraduates, which shows that it is particularly important to do a good job of student practice. When choosing practice units, teachers should make as many investigations as possible, select hotels with standardized management, rapid development and reasonable post settings. It is necessary to sign practice contracts with hotels, if conditions permit, to standardize the practice work that hotels should provide to trainees. And it should form long-term mechanism through long-term cooperation with hotels. In addition, it improves trainees' satisfaction and strengthens their retention intention.

From the perspective of students. Students majoring in tourism management should realize that, unlike other industries, the tourism industry pays more attention to operational skills [7]. As undergraduate graduates, it is impossible for them to enter the management position at the beginning of their work. They should be fully prepared to start from the grass-roots level and bear hardships. They should also overcome the viewpoint that entering the tourism service industry is a "big talent, small use" and "the lowest choice". In addition, students should practice more, learn more and ask more in the hotel practice process, maintain a positive communication with colleagues, take the initiative to adapt to the working environment, accumulate practical experience, form a healthy view of employment.

\section{Acknowledgements}

This paper is sponsored by project fund from Leading Group Office of Jilin Provincial Educational Science (Project Title: Research on the impact of practice on tourism management students' career intentions; Contract NO. GH170647). In addition, it is also sponsored by the grant from the Higher Education Research Institute of Jilin Engineering Normal University.

\section{References}

[1] Information on http://www.ctnews.com.cn

[2] Z.Y. He: Journal of Liaoning Economic Vocational Technological Institute, Vol. 9 (2007) No.4, p.98-99.

[3] X.Z. Yang, S.M. Wang, S.J. Ye and C.C. Tao: Higher Agricultural Education, Vol. 25 (2008) No.11, p.82-87.

[4] J. Bi: Journal of Henan Polytechnic University (Social Sciences), Vol. 12 (2011) No.3, p.300-305.

[5] N.T. Jiao, J.C. Dong and W.S. Xu: Chinese Vocational and Technical Education, Vol. 22 (2014) No.24, p.84-89.

[6] F.Y. Bao: Journal of Sichuan Tourism University, Vol. 17 (2015) No.3, p.78-81.

[7] S.J. Sun: An Empirical Study on the Internship Satisfaction and Career Degree of Hotel Management Specialty in Higher Vocational College-Taking ZX College as an Example (MS., Guangxi University, China 2017), p.34.

[8] C. Giousmpasoglou: International Conference on Tourism (Rostock, Germany, September 8-13, 2013). Vol. 1, p.775-782.

[9] F. Seyitoğlu and S. Yirik: Asia Pacific Journal of Tourism Research, Vol. 20 (2015) No.1, p.1414-1429. 